\title{
Development of responses based on IPCC and "what-if?" IWRM scenarios
}

\author{
V. Giannini ${ }^{1,2}$, L. Ceccato ${ }^{1}$, C. Hutton ${ }^{3}$, A. A. Allan $^{4}$, S. Kienberger ${ }^{5}$, W.-A. Flügel ${ }^{6}$, and C. Giupponi ${ }^{1,2}$ \\ ${ }^{1} \mathrm{Ca}$ ' Foscari University of Venice, Italy \\ ${ }^{2}$ Fondazione Eni Enrico Mattei, Venice, Italy \\ ${ }^{3}$ GeoData Institute, Southampton, UK \\ ${ }^{4}$ Centre for Water Law, Policy and Science, University of Dundee, UK \\ ${ }^{5}$ Centre for Geoinformatics, University of Salzburg, Salzburg, Austria \\ ${ }^{6}$ Department of Geoinformatics, Hydrology and Modelling, Friedrich-Schiller University Jena, Germany
}

\begin{abstract}
This work illustrates the findings of a participatory research process aimed at identifying responses for sustainable water management in a climate change perspective, in two river basins in Europe and Asia. The chapter describes the methodology implemented through local participatory workshops, aimed at eliciting and evaluating possible responses to flood risk, which were then assessed with respect to the existing governance framework. Socio-economic vulnerability was also investigated developing an indicator, whose future trend was analysed with reference to IPCC scenarios. The main outcome of such activities consists in the identification of Integrated Water Resource Management Strategies (IWRMS) based upon the issues and preferences elicited from local experts. The mDSS decision support tool was used to facilitate transparent and robust management of the information collected and communication of the outputs.
\end{abstract}

\section{Introduction}

The BRAHMATWINN research project has planned a participatory process to integrate scientific and stakeholders' knowledge to deal with water management, climate change, and alpine mountain regions in Europe and Asia. Two parallel streams of research have been developed. On the one hand, research activities in the various disciplinary fields, such as climatology, hydrology, sociology, economics, and governance, relevant for integrated water resources management (IWRM) and the development of adaptation responses. On the other hand, a series of local workshops in the Upper Danube River Basin (UDRB) and the Upper Brahmaputra River Basin (UBRB), have been developed. The first outcome of this integrated and iterative process - the Integrated Indicator Table (IIT) - was described in Chapter 6.

Local actors' (LA) knowledge should be used in social and ecosystem management, in order to integrate scientific with local knowledge. Thus the participation of local actors can contribute significantly to the achievement of project outcomes that are better suited to fulfil local needs (de La Vega-Leinert et al., 2008), increasing the impacts of research

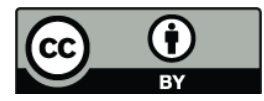

Correspondence to: V. Giannini (valentina.giannini@feem.it) efforts. Participatory processes enable sharing information between scientists and stakeholders, creating new opinions, addressing problems, combining expertise, in order to reach agreements and compromise solutions taking into account all interests at stake (Reed, 2008; Renn, 2006).

Besides the relevance given to public participation in IWRM, the necessity of utilizing also more effective tools to support decision making processes has emerged, giving more importance to information and communication technologies (ICT), such as Decision Support System (DSS) tools (Mysiak et al., 2005). In a DSS a conceptual model can be formalized through a joint effort integrating knowledge from disciplinary and local experts, bridging the gap between "hard science" and qualitative assessments (Sgobbi and Giupponi, 2007).

Future socio-economic vulnerability scenarios following the IPCC SRES projections A1, A2, B1, B2 (IPCC, 2000) for the time steps 2000, 2020 and 2050 have been modelled, which are based on the present day vulnerability modelling (Hutton et al., 2011; Kienberger et al., 2009b). The scenario modelling has been carried out in the Salzach River basin and in the Assam NE-India case studies, under the same scenario conditions and following a joint methodology. A condensed vulnerability index, consisting of proxy variables, has been identified and its indicators projected using a correlation with future GDP and population scenarios. 
In this chapter we illustrate some of the methods and findings relative to the analysis of the effectiveness of the responses identified to cope with climate change. We present these as a methodological and operational proposal for the management of decision processes in a participatory context during the development of Integrated Water Resources Management (IWRM) options adapting to likely climate change impacts. The feasibility of these responses and strategies are then validated with reference both to the existing governance frameworks in place, and to projected future governance characteristics inferred from the IPCC SRES Scenarios (IPCC, 2000).

\section{Role within the integrated project}

The participative activities presented in this chapter, as well as those that were carried out in earlier phases of the project, made it possible to maintain open communication with local actors, allowing the project consortium to acquire local knowledge and orient research activities towards needs. They also provided a means of carrying out the twinning of the two river basins, shedding light on commonalities and distinct features. As far as the results of the two workshops discussed in this chapter are concerned, the phases of climate change scenarios presentation and brainstorming set the foundations for the DSS Design, and enabled the setting up of the activities on a common and shared framework, i.e. the features of each river basin. These phases also contributed to raise awareness about climate change dynamics, and to the state-of-the-art downscale modelling approaches. The phases of DSS Design and Analysis of Options carried out by means of the mDSS software raised great interest among the participants, who were thus involved in the project activities, exposed to preliminary results, and contributed to orient the final phases of the project. Several participants appreciated the use of public domain software in particular, which provided a perspective of possible reutilisation of the approach proposed in local decision problems.

\section{Methods}

\subsection{The DSS Design and its implementation for the anal- ysis of responses}

The method applied for the evaluation of the responses to cope with flood risk is developed within the NetSyMoD framework designed for natural resources management in a participatory setting (refer to Fig. 1 in Chapter 6; Giupponi et al., 2008). NetSyMoD is based on the DPSIR causal framework (Driving forces, Pressures, State, Impacts, and Responses; EEA, 1999), which enables the organization of information, the structuring of issues, and the identification of solutions (i.e. Responses). The NetSyMoD approach is divided into six phases, two of these phases, DSS Design and Analysis of Options, were the object of the activities carried out at the two workshops discussed in this chapter. The DSS Design phase consists of system specification and development of software tools capable of managing the data required for informed and robust decisions. The Analysis of Options is performed with the mDSS software (Mulino DSS), a Decision Support System (DSS) tool providing capabilities for formalising, supporting and documenting the decision process and facilitating the adoption of Multi Criteria Decision Methods (MCDM) in a multi-actor context.

As an output of the implementation of the two steps mentioned above, substantial contributions to the design and evaluation of a set of alternative responses were obtained by means of group elicitation techniques and through the application of the DSS tool. The process for the identification of the IWRM strategies to be assessed, as described in Chapter 6, was based upon a series of workshops providing outputs that were organised in form of an Integrated Indicator Table (IIT). In the IIT (refer to Fig. 1) all the elements emerged from the interactions with stakeholders relevant for the identification of possible IWRM strategies and climate change adaptation were categorised as Responses (according to the DPSIR framework) and listed according to four broad categories:

1. ENG-LAND: Engineering Solutions and Land Management (response options would therefore include for example dam construction, river network maintenance, river training works, soil conservation practices, control of glacier lake outburst floods, forest management, renaturation, etc.);

2. GOV-INST: Investments in Governance and Institutional Strength (response options including accountability and transparency in government actions, enforcement of existing regulations, flood insurance, etc.);

3. KNOW-CAP: Knowledge Improvement and Capacity Building (response options including awareness raising activities, dissemination of scientific knowledge, strengthen traditional knowledge, training of public employees, environmental monitoring, etc.);

4. PLANNING: Solution based on planning instruments (response options would then include design and implementation of relief and rehabilitation plans, hazard zoning, disaster risk management, land-use planning etc.).

Two new workshops were organised, one for the UDRB in Salzburg, Austria (October 2008) and one for the UBRB in Kathmandu, Nepal (November 2008) to evaluate the relative effectiveness of the four Response categories. The workshops were divided into five phases.

1. First the goals of the workshop were defined, and then scenarios based on downscaled climate change model results were illustrated to introduce possible impacts of climate change at local level (see Dobler et al., 2011). 


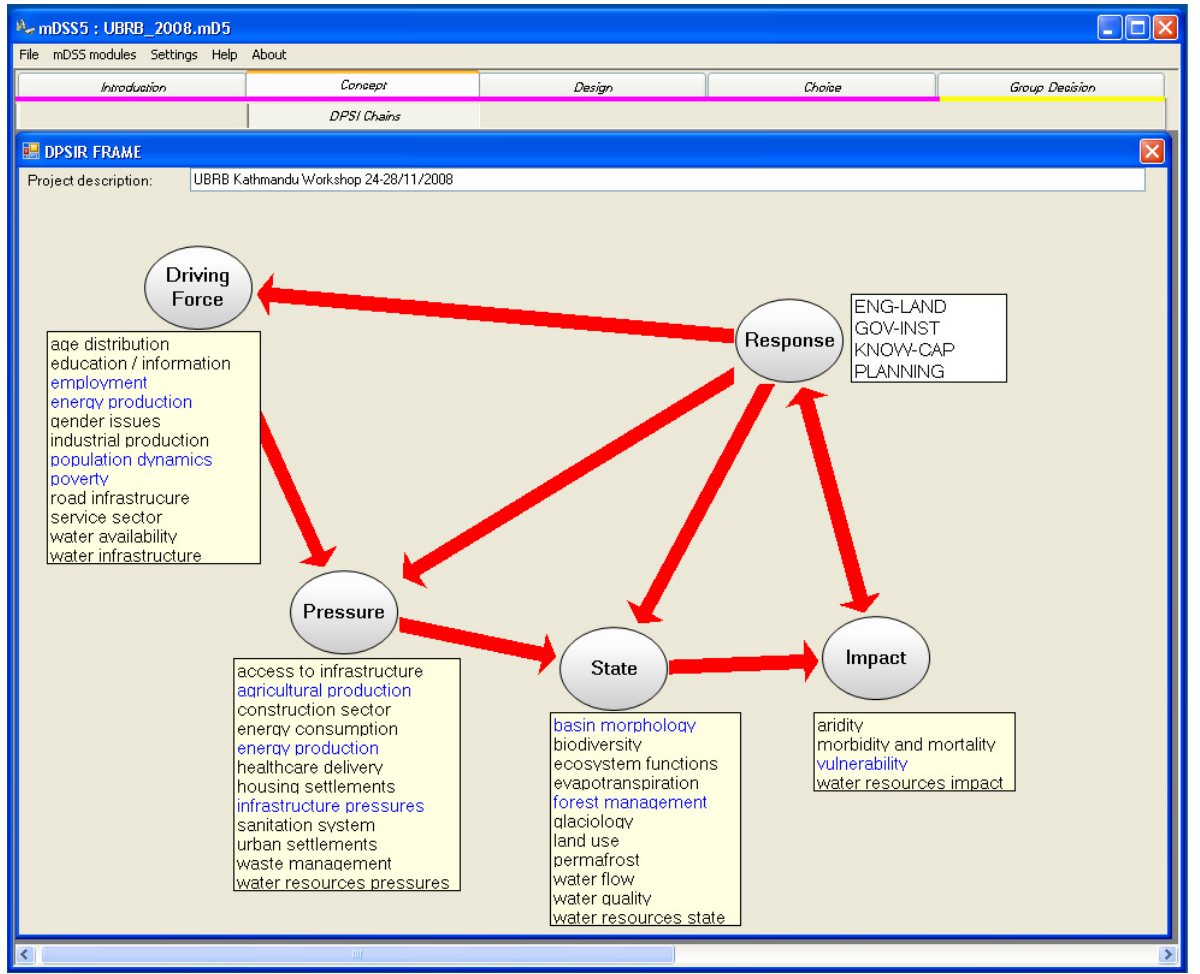

Figure 1. The conceptualisation of the information base stored in the IIT within the DPSIR framework (screenshot of the mDSS software).

2. The second component was a brainstorming session carried out to validate and specify the responses within the four categories that had been identified during previous workshops.

3. In the third phase participants selected the criteria for the evaluation of responses, attributing scores to the Sub-domains listed in the IIT.

4. In the fourth phase participants weighted the selected criteria.

5. In the fifth phase of the workshops the Analysis Matrix (AM) was created using criteria and responses. Participants compiled the Analysis Matrix to evaluate the potential effectiveness of each of the responses (columns) in coping with the issues expressed by the criteria (rows) applying a Likert scale ranging from 1 "very high effectiveness" to 5 "very low effectiveness".

All compiled AMs were imported into the mDSS software, for Multi-Criteria Analysis (MCA) and Group Decision Making (GDM), which enabled the evaluation of the relative effectiveness of alternative responses through MCA performed by decision rule ELECTRE III (Belton and Stewart, 2002). Following another possibility individual preferences were processed in the Group Decision Making component of mDSS using the Borda rule (de Borda, 1781).

\subsection{Validation of response strategies}

In order to validate the categorised possible response strategies identified by stakeholders (Sect. 3) against the relevant governance frameworks, an effort was made to compare these Responses to the governance and policy positions assessed in Chapter 4. The response strategies, at least in the short term, need to be seen in the context of these assessments because the governance and policy frameworks will have a strong bearing on the extent to which responses may be considered potentially successful or not (Hague Ministerial Declaration, 2000). The future scenarios into which this work has been incorporated are those proposed by the IPCC in 2000 (IPCC, 2000) in the Special Report Emission Scenarios (SRES) and their associated storylines (A1, A2, B1 and B2).

No projections as to the governance environment have been made in these storylines. In order therefore to evaluate the extent to which these preferred solutions would be practical over the period of the time slices identified in the project (up to 2080) and the time horizon envisaged by the IPCC scenarios, inferences were derived from the socio-economic and physical characteristics identified in the SRES storylines as regards the potential governance situation in 2100 . This then allows an evaluation of those response strategies that seem most appropriate for the storylines based on the projected governance situations. This process was applied to the response strategies related to the Assamese context. 
Table 1. Criteria selected by LAs from the Integrated Indicators Table.

\begin{tabular}{lclc}
\hline Criteria selected UDRB & Weight & Criteria selected UBRB & Weight \\
\hline Vulnerability (ENV) & 0.144 & Vulnerability (ENV) & 0.145 \\
Ecosystem functions (ENV) & 0.143 & Population dynamics (SOC) & 0.132 \\
Housing settlements (SOC) & 0.138 & Poverty (SOC) & 0.125 \\
Infrastructure pressures (SOC) & 0.133 & Basin morphology (ENV) & 0.125 \\
Agricultural production (ECON) & 0.111 & Forest management (ENV) & 0.113 \\
Construction sector (ECON) & 0.099 & Agricultural production (ECON) & 0.103 \\
Population dynamics (SOC) & 0.097 & Energy production (ECON) & 0.101 \\
Basin morphology (ENV) & 0.091 & Infrastructure pressures (SOC) & 0.100 \\
Energy consumption (ECON) & 0.043 & Employment (ECON) & 0.056 \\
\hline
\end{tabular}

The SRES storylines therefore had to be deconstructed to identify the particular strands relevant to water, land and disaster management and the resulting projected governance frameworks used to flesh-out the SRES storylines. These strands include the (i) potential for institutional and international co-operation; (ii) the relative balancing of economic, social and environmental concerns; (iii) the capacity for land use control; and (iv) the likelihood of effective enforcement. Each response strategy was then evaluated against the projected governance strengths and weaknesses derived from the SRES storylines, and against the legal and institutional reality in the relevant basin state.

\subsection{Vulnerability scenarios}

The methodology for the vulnerability scenarios comprises the following key-steps and has been carried out in the same way in the European and Asian case studies:

- Construction of a correlation analysis between the vulnerability score and the individual indicators and selection of five key variables that are highly correlated with the vulnerability score.

- With the key variables a multivariate regression analysis has been performed to identify the predictors of the level of vulnerability. Within the Salzach River basin case study two methodologies have been tested, a regression analysis identifying single predictors for the whole case study area (ordinary least squares method), and a geographically weighted regression which identifies for each location (in our case grid cells) individual, location-based predictors.

- A parallel step involves the correlation between past GDP and population data and past data of the key variables to identify their existing relationship.

- Taking the future GDP and population projections under the four SRES scenarios in consideration, values for the future key variables under the four scenarios have been calculated.
- Applying the regression formula identified in step 2, projected vulnerability indices have been calculated for the four scenarios for the time steps 2020 and 2050.

- In a final step the data has been normalised (scale range 0-100) according to the values of 2000 to identify growth and decline of vulnerability among the different scenarios.

- Visualisation and map production was the last step elaborated in this procedure.

\section{Results and deliverables provided}

\subsection{Local actors evaluation of responses}

Local actors (LAs) identified the three most important criteria for each of the three dimensions, economic, environmental and social, i.e. the three pillars of sustainable development, converging in both basins on the same five criteria out of nine, choosing from a set of 40 criteria listed in the IIT (15 social criteria, 17 environmental criteria, and 8 economic criteria) (Ceccato et al., 2010).

LAs then expressed the relative importance of every criterion, which will be used to rank the alternative IWRM responses. On average, in both river basins, the highest weight was given to the "Vulnerability" criterion (Environmental pillar) (see Table 1). Five out of nine criteria selected were common to both basins: Vulnerability, Population dynamics, Infrastructure pressure, Basin morphology, and Agricultural production. The elaboration of the average Analysis Matrix (AM) shown in Table 2 illustrates that no category of response prevails. All the average responses (listed in columns) are in a range between "very high effectiveness" and "medium effectiveness". We can, thus, say that all the responses are considered to be potentially effective to cope with flood risk.

Last but not least, the relative ranking of the alternative responses was carried out by performing Multi Criteria Analysis and Group Decision Making. The application of 
Table 2. Analysis Matrices: average values of LAs' evaluations on the potential effectiveness of each response in coping with the issues expressed by the criteria (rows) by means of a Likert scale ranging from 1 "Very high effectiveness" to 5 "Very low effectiveness".

\begin{tabular}{lcccc}
\hline Analysis Matrix UDRB & PLANNING & KNOW-CAP & GOV-INST & ENG-LAND \\
\hline Vulnerability (ENV) & 2.33 & 2.67 & 2.50 & 2.67 \\
Ecosystem functions (ENV) & 2.86 & 2.43 & 2.29 & 3.43 \\
Housing settlements (SOC) & 2.00 & 2.43 & 2.57 & 2.71 \\
Infrastructure pressures (SOC) & 2.43 & 2.14 & 2.57 & 2.00 \\
Agricultural production (ECON) & 2.86 & 3.14 & 2.71 & 2.57 \\
Construction sector (ECON) & 2.14 & 3.29 & 2.57 & 2.43 \\
Population dynamics (SOC) & 2.86 & 3.00 & 2.29 & 3.29 \\
Basin morphology (ENV) & 2.71 & 2.57 & 3.43 & 3.29 \\
Energy consumption (ECON) & 2.86 & 2.43 & 2.57 & 2.86 \\
\hline Average & 2.56 & 2.68 & 2.61 & 2.80 \\
\hline & & & & \\
\hline Analysis Matrix UBRB & PLANNING & KNOW-CAP & GOV-INST & ENG-LAND \\
\hline Vulnerability (ENV) & 1.71 & 2.43 & 2.24 & 1.95 \\
Population dynamics (SOC) & 1.76 & 2.52 & 2.33 & 3.19 \\
Poverty (SOC) & 2.43 & 2.62 & 2.00 & 3.33 \\
Basin morphology (ENV) & 2.38 & 2.67 & 3.10 & 2.43 \\
Forest management (ENV) & 1.86 & 2.10 & 2.10 & 1.95 \\
Agricultural production (ECON) & 2.15 & 2.50 & 2.48 & 2.29 \\
Energy production (ECON) & 2.19 & 3.00 & 2.43 & 2.10 \\
Infrastructure pressures (SOC) & 2.00 & 2.86 & 2.67 & 2.19 \\
Employment (ECON) & 2.43 & 2.57 & 2.43 & 3.52 \\
\hline Average & 2.10 & 2.58 & 2.42 & 2.55 \\
\hline
\end{tabular}

ELECTRE III (Fig. 2) shows that LAs of both river basins evaluated the PLANNING solution as the most promising one. Using the Group Decision Making (GDM) tool of mDSS, considering the Borda mark the PLANNING category is also the preferred solution (Ceccato et al., 2010). The comparison of these independent results confirmed that PLANNING instruments are the most promising responses in terms of effectiveness to cope with flood risk under climate change impacts. We recognise, therefore, that very similar results were recorded in the two river basins, confirming that, notwithstanding the differences in their environmental and socio-economic conditions, the areas present certain similarities not only regarding the problems to address, but also regarding the expectations of possible solutions.

From the governance perspective, the comparison of the responses against the legal and institutional frameworks in 2007 and over the scenario time periods revealed that the B1 storyline fitted best with the responses put forward by LAs in response to the local issues, with A2 being least appropriate (Table 3). Based on the number of strategies which were best suited for each storyline, B1 again came out as the winner, being most associated with ten strategies, but this time B2 clearly emerged as the worst, being best associated with only one. In Assam, however, the local governance context is currently strongest in relation to strategies that enforce an A1 scenario, suggesting there is a mismatch between what stake- holders believe are the policy and strategic approaches that should be taken in order to alleviate vulnerability on the one hand, and the approach taken, at least in the short to medium term, by government and regulatory authorities.

\subsection{Implementation for the Salzach River basin case study}

In the modelling of socio-economic vulnerability in the Salzach River catchment 52 indicators have been identified describing various domains of vulnerability (see Kienberger et al., 2009a). Through the application of spatial correlation those indicators have been selected which have a higher correlation value than 0.5 . Out of the 14 remaining indicators those have been selected which show a compromise with a high correlation value $(>0.7)$ and a significant number of correlating indicators. The following five key indicators have been identified:

\footnotetext{
- Number of houses with 1 or 2 households $(\times 1)$

- Number of industrial buildings $(\times 2)$

- Number of labours in agriculture $(\times 3)$

- Number of academics $(\times 4)$

- Number of male full-time employees $(\times 5)$
} 



Figure 2. UDRB (top) and UBRB (bottom): ELECTRE III Analysis of alternative Responses. On the left side we can see the applied criteria weights and thresholds, while on the right side the ELECTRE III window appears with the final ranking (screenshot of the mDSS software). 
Table 3. Evaluation of suitability of Assam response strategies against projected governance characteristics of SRES Scenarios.

\begin{tabular}{|c|c|c|c|c|c|c|}
\hline Issue & Response strategy & A1 & A2 & B1 & B2 & Time Slice \\
\hline $\begin{array}{l}\text { Awareness of population on } \\
\text { risks, conservation and WRM }\end{array}$ & $\begin{array}{l}\text { Increase awareness of the population } \\
\text { on risks, conservation and WRM }\end{array}$ & 2 & 1 & 4 & 3 & $2001-2020$ \\
\hline $\begin{array}{l}\text { Integration of research in } \\
\text { decision-making }\end{array}$ & $\begin{array}{l}\text { Integration and coordination among } \\
\text { different sectors of research and } \\
\text { decision making }\end{array}$ & 3 & 2 & 4 & 1 & $2001-2020$ \\
\hline \multirow[t]{2}{*}{$\begin{array}{l}\text { Community involvement in } \\
\text { decision making }\end{array}$} & $\begin{array}{l}\text { Improve community involvement and } \\
\text { foster participatory processes for } \\
\text { decision making }\end{array}$ & 1 & 3 & 2 & 4 & $2001-2020$ \\
\hline & $\begin{array}{l}\text { Foster livelihood practices based on } \\
\text { conservation, rehabilitation and } \\
\text { sustainability }\end{array}$ & 2 & 1 & 4 & 3 & $2020-2050$ \\
\hline \multirow[t]{3}{*}{ Early warning system } & Early warning system & 4 & 1 & 3 & 2 & $2001-2020$ \\
\hline & Disaster risk management & 4 & 1 & 3 & 2 & $2001-2020$ \\
\hline & Hazard zonation & 3 & 1 & 4 & 2 & $2001-2020$ \\
\hline IWRM & Design and implement IWRM plans & 3 & 1 & 4 & 2 & $2001-2020$ \\
\hline \multirow{4}{*}{$\begin{array}{l}\text { Long term vision and measures } \\
\text { vs. Short term engineering } \\
\text { solutions }\end{array}$} & Multi-purpose dam construction & 4 & 2 & 3 & 1 & $2020-2050$ \\
\hline & Flood and erosion control & 3 & 4 & 2 & 1 & 2020-2050 \\
\hline & Land use planning & 2 & 1 & 4 & 3 & $2001-2020$ \\
\hline & $\begin{array}{l}\text { Environmental impact assessment for } \\
\text { new dams }\end{array}$ & 3 & 1 & 4 & 2 & $2001-2020$ \\
\hline \multirow[t]{3}{*}{ Relief and rehabilitation } & $\begin{array}{l}\text { Design and implement relief and } \\
\text { rehabilitation plans }\end{array}$ & 3 & 1 & 4 & 2 & $2001-2020$ \\
\hline & Soil conservation efforts & 1 & 4 & 2 & 3 & 2001-2020 \\
\hline & Renaturation & 1 & 4 & 2 & 3 & 2020-2050 \\
\hline \multirow[t]{2}{*}{$\begin{array}{l}\text { Policy making and implementa- } \\
\text { tion of laws }\end{array}$} & $\begin{array}{l}\text { Accountability and transparency in } \\
\text { government actions }\end{array}$ & 3 & 2 & 3 & 2 & $2020-2050$ \\
\hline & $\begin{array}{l}\text { Implement and enforce existing laws } \\
\text { and design new and more effective laws }\end{array}$ & 3 & 2 & 3 & 2 & $2001-2020$ \\
\hline $\begin{array}{l}\text { Coordination among } \\
\text { institutions }\end{array}$ & $\begin{array}{l}\text { Resolve conflicts and strengthen } \\
\text { coordination among institutions }\end{array}$ & 3 & 2 & 4 & 1 & $2001-2020$ \\
\hline \multirow[t]{2}{*}{$\begin{array}{l}\text { Inter-state conflict, } \\
\text { cross boundary issues }\end{array}$} & $\begin{array}{l}\text { Inter-state coordination and conflict } \\
\text { resolution }\end{array}$ & 4 & 2 & 3 & 1 & $2020-2050$ \\
\hline & Totals & 52 & 36 & 62 & 41 & \\
\hline
\end{tabular}

It is interesting to note that these indicators have gained high LA weights in the sub-domain ranking. So therefore the indictors do not only represent from the statistical point of view an appropriate selection but reflect some of the highest ranked indicators. However, it is important to note that the weights have not been considered in the correlation analysis.
Concluding the steps outlined above, in the final results it can be observed that the general pattern among the different scenarios shows a similar distribution, with slight changes in its peak values. First of all it is important to note, that some areas show a vulnerability value of zero. This is due to the fact that the selected five key indicators derive from the census data. This means that only vulnerability values higher than zero exist in those areas where population is present. 

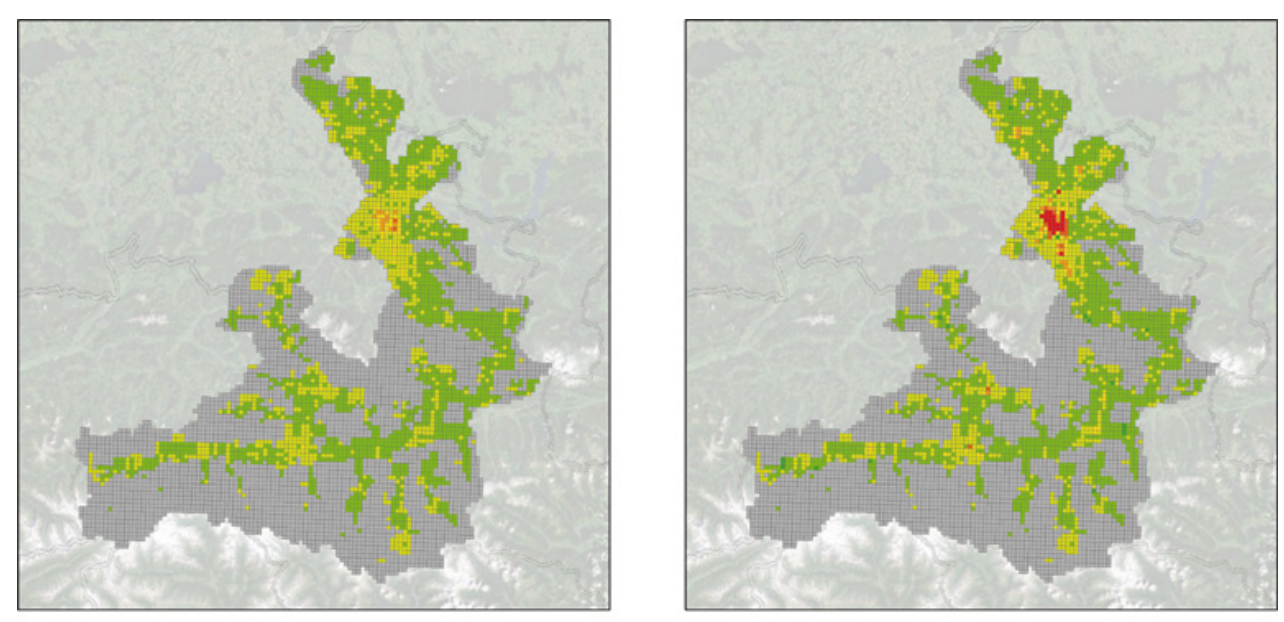

2020

A1

2050

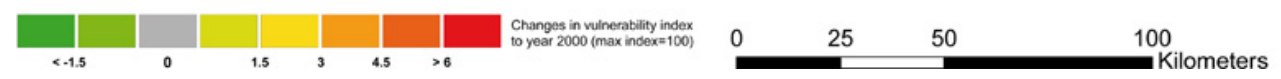

Figure 3. Change of vulnerability value within the A1 scenario to the reference year 2000.

This is an interesting fact following the general discussion on vulnerability, where it is argued that vulnerability only exists where humans are affected. In the vulnerability analysis carried out in Chapter 4 it was also assumed that vulnerability can exist in general everywhere and is also constituted by land use assets. However, for the purpose of specific vulnerability scenarios, which still carry some uncertainty itself, this is a valid approach to follow.

The highest vulnerability values can be observed around the city of Salzburg, which of course is the most densely populated area in the case study, where the indicators of houses with one to two households, male full-time employees, academics and industrial buildings show high values. Additionally to that rural areas with a high proportion with single houses and a higher number of labours in the agricultural sector have slightly higher values than surrounding areas. This concentrates in the case study around important central towns and villages. The highest vulnerability scores can be observed within the scenarios A1 and B1, whereas the absolutely highest vulnerability score (113.79) can be observed in the A1 scenario (see Fig. 3), followed by B1 with 111.65. Lower values show the 2-group scenarios A2 and B2 which have a more regional oriented focus than the globalised 1-group scenarios. The lowest vulnerability score is represented through the $\mathrm{B} 2$ scenario with a value of 107 . The A2 scenario has a maximum value of 109.39 for 2050 .

Examining the change rates among the different scenarios for 2020 and 2050 in reference to the baseline year 2000 a general increase in and around the city of Salzburg can be observed (which show the highest increase in vulnerability) and other areas with higher values of the key indicators. Those areas show all an increase in vulnerability, whereas the ur- ban agglomeration has the highest values for 2050 within the scenarios A1 and B1. A decrease in vulnerability can be observed in strongly rural dominated areas. This is also due to the fact that regression analysis shows negative trends for the indicators of labours in the agricultural sector and interestingly in the number of male fulltime employees.

A similar picture as described above applies for the maximum change rates within the different scenarios for the time span between 2000 and 2050. Highest maximum increases show the A1 $(+13.79 \%), \mathrm{B} 1(+11.65 \%)$ followed by A2 $(+9.39 \%)$ and B2 $(+7 \%)$ scenario. A significant decrease in vulnerability can be observed in the A1 scenario with a maximum decrease value of $-2.24 \%$. Therefore it can be observed that the A1 scenario shows a larger dispersion of its value range than the other scenarios. Maximum decrease values are followed by B1 $(-1.89 \%), \mathrm{A} 1(-1.52 \%)$ and $\mathrm{A} 2$ $(-1.14 \%)$. The A2 scenario shows both, low increase but also low decrease values. However, in general it can be observed that the mean value of change rates is $\sim 0 \%$. It shows (Fig. 4) that most of the raster cells do have a low decrease or increase and that the majority of units decrease. This also follows the observation in the change maps, where the increase is limited to highly urbanised areas, which only occupy a small area.

It can be summarised that urban and central villages in rural areas show a significant increase in vulnerability. However, from a spatial point of view most areas show a decrease in vulnerability, which are mostly less asset driven because of its rural characteristic. The methodology applied gives an overall estimation of vulnerability, but as those estimations inherit an unspecified high uncertainty they might only be applied to identify general future trends. 
Table 4. Scenarios are based upon the work carried out by TERI (India) showing the projected GDP and Population outcomes for all India based upon the SRES scenarios (GDP $\times 1013$ Rupees, Population in millions).

\begin{tabular}{ccccccccc}
\hline & \multicolumn{2}{c}{ A1 } & \multicolumn{2}{c}{ A2 } & \multicolumn{2}{c}{ B1 } & \multicolumn{2}{c}{ B2 } \\
\hline & GDP & Pop & GDP & Pop & GDP & Pop & GDP & Pop \\
\hline 1990 & 0.886 & 846 & 0.886 & 846 & 0.886 & 846 & 0.886 & 846 \\
2020 & 8.924 & 1.291 & 5.094 & 1.102 & 5.866 & 1.228 & 3.833 & 1.012 \\
2050 & 33.426 & 1.572 & 14.298 & 1.646 & 19.027 & 1.298 & 9.304 & 1.646 \\
\hline
\end{tabular}



Figure 4. Histogram of change rates for the A1 scenario between 2000 and 2050.

\subsection{Implementation for the Assam case study}

The aim of the Assam component of the study is to investigate how different scenarios of socioeconomic development will mitigate the impact of climate change in the Assam test site. The basis of this analysis is adopted from socioeconomic scenarios developed for India by TERI (TERI, 2006), an independent not-for-profit research institution in India (Table 4). The scenarios are developed on the basis of the Intergovernmental Panel on Climate Change (IPCC) Special Report on Emissions Scenarios (SRES) scenarios. The conceptualization of the scenarios is based on two dimensions of policy directions and social values. The framework focuses on where policy direction is either inward-looking or globally integrated and where social values focus on economic growth or more localised social values and environmental consequences. The combinations results of socioeconomic scenarios can be used to investigate future impacts of climate change vulnerability which relates primary to governments focus and priorities. Scenarios A2 and B2 reflect a more inward-looking policy, while scenarios A1 and B1 reflect stronger integration with the global community for regulation and economic growth.
TERI used six factors (changes in population growth, GDP projections, food grain demand, demand for water, demand for electricity and demand for wood) to investigate how the four scenarios could impact on socioeconomic vulnerability to climate change for India for the 1990s and projected to the 2020s and 2050s (Table 4). The values are adopted for this study to investigate how government priorities could impact on socio-economic vulnerability in the Assam Study Area under the four scenarios.

In Chapter 4 estimates of socioeconomic vulnerability in 2001 (and also for specific domains of sensitivity and adaptive capacity) to climate hazards (e.g. floods, droughts, bank erosion) were derived for communities and Tehsils in the Assam Study Area. The scores were exponentially scaled such that they range between 0.001 and 100 (the higher the score the higher the level of vulnerability), with emphases on the tail of the distribution to identify the most vulnerable communities. Figure 5 shows vulnerability quintiles for the Assam study area in 2001 which is the last time a clear picture of vulnerability based upon the census and Landsat imagery is available (see Chapter 4).

In this follow-up study to the work presented in Chapter 4, the main aim is to investigate by how much the level of the estimated vulnerability for each Tehsil will increase or decrease depending on governments policy directions and social values under the four scenarios developed by TERI. To do this, we first identify all the individual variables that are highly correlated $(> \pm 0.5)$ with the vulnerability score. In all 18 individual variables were identified to have a high correlation with the overall vulnerability score. Tehsils with high engagement in subsistence agriculture and poor housing materials are more likely to be vulnerable. Ownership of assets such as television, telephone, scooter, motor, cycle or moped is negatively correlated with vulnerability scores. It is interesting to note that Tehsils with high dependency of forest ecosystems e.g. using firewood for cooking are more likely to be vulnerable compared to those who use LPG for cooking. A multivariate (regression) analysis is then used to identify the predictors of level of the vulnerability. To satisfy the assumptions of normality and constant variance, the vulnerability scores were log transformed. It is important to note that there was a high level of collinearity between some of the 

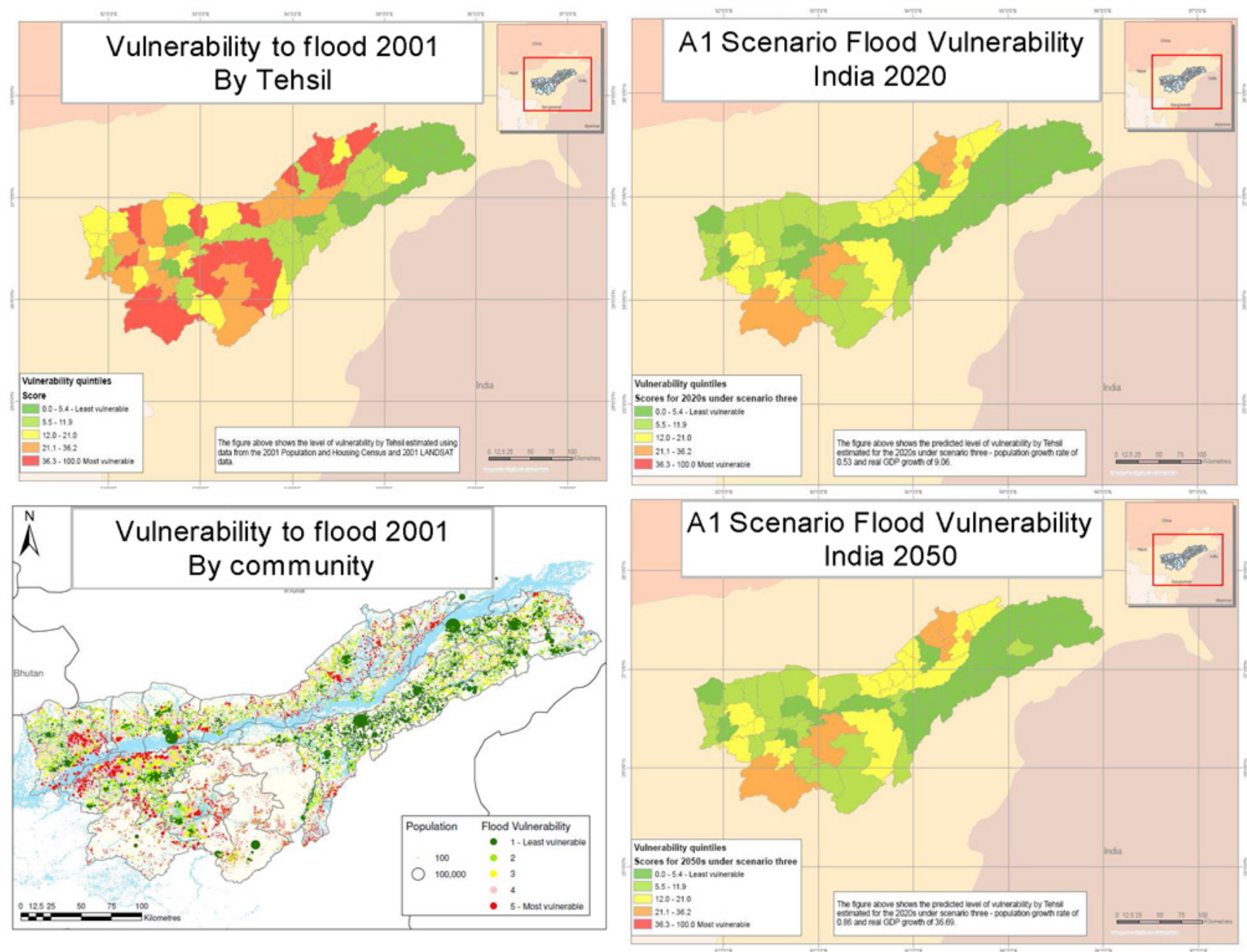

Figure 5. Estimates of vulnerability based upon know variables for 2001 at both a community and Tehsil level. The estimates of vulnerability to flood in 2020 and 2050 under SRES A1 (example) utilise TERI estimates of GDP and poulation and model the impact of these estimates on specific indicators of overall vulnerability.

variables. Where two or more variables were collinear, only the strongest predictor was included in the model. The estimated Adjusted R-square indicates that the five significant indicators explain $91.7 \%$ of the variability in vulnerability scores.

\section{Contribution to sustainable IWRM}

The results of BRAHMATWINN show that the implementation of NetSyMoD is useful for developing responses which are then evaluated as effective. The development of responses is, in fact, based on an iterative process which integrates knowledge coming from different disciplines and local actors. The two parallel participatory processes, on the one hand, allowed the understanding of the visions and preferences of LAs regarding the sustainable management of water resources. On the other hand, highlighted that the infor- mation and tools proposed by the researchers was adequate to address local actors (e.g. decision makers and end-users) needs.

The methodology used enabled to frame the issues in a coherent manner and, thus, to focus the discussion. This, in a subsequent phase of the project, led to further refinements of the responses to cope with flood risk.

This result validates the motivations which triggered the BRAHMATWINN project design and led to develop a twinning river basin research approach, characterised by a strictly coordinated and combined series of participatory activities in the two twinning basins. 


\section{Conclusions and recommendations}

The experimental application of the NetSyMoD approach to the twinned river basins provided the BRAHMATWINN project with an effective interface between the research activities and potential beneficiaries, in the case studies located in Asia and Europe.

The participative activities presented in this chapter made it possible to maintain an open communication interface with LAs, allowing the BRAHMATWINN researchers to learn from them and orient research activities. The phase of DSS design that was carried out by means of the mDSS software was followed and understood by local actors, who were able to influence the development of the following project phases.

From the perspective of assessing the potential effectiveness and feasibility of response strategies, the mismatch between what stakeholders believe are the policy and strategic approaches that should be taken in order to alleviate vulnerability on the one hand, and the approach taken, at least in the short to medium term, by government and regulatory authorities must raise questions as to the quality of the involvement of stakeholders in decision-making processes in Assam.

The vulnerability analysis shows that GDP and population growth impacts on household and community factors that predict socioeconomic vulnerability to climate hazards, such as the proportion of the population working in agriculture, proportion of roads that are metalled, proportion of households with a television, proportion of houses with burnt brick wall and proportion of households using firewood for cooking. The impact of GDP and population growth is highest in areas where levels of vulnerability are already high. The results depict that a slow growth in population with a concurrent rapid growth in GDP is important in reducing levels of vulnerability.

Acknowledgements. We would like to acknowledge the following BRAHMATWINN research partners for helping organize the workshops: Institute for Atmospheric and Environmental Sciences, Goethe University Frankfurt (Germany); Department for Geography, Ludwig-Maximilians University, Munich, Germany; ICIMOD, Kathmandu, Nepal; Royal University of Bhutan, Thimphu (Bhutan); Indian Institute of Technology Roorkee, Roorkee (India).

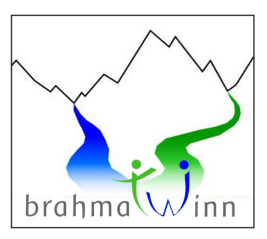

The interdisciplinary BRAHMATWINN EC-project carried out between 2006-2009 by European and Asian research teams in the UDRB and in the UBRB enhanced capacities and supported the implementation of sustainable Integrated Land and Water Resources Management (ILWRM).

\section{References}

Belton, V. and Stewart, T. J.: Multiple criteria decision analysis, Kluwer Academic Publishers, Boston, 2002.

Ceccato, L., Giannini, V., and Giupponi, C.: A participatory approach to assess the effectiveness of responses to cope with flood risk, FEEM Working Paper, 28, 2010.

de Borda, J.-C.: Mathematical derivation of an election system, Isis, 44, 42-51, 1781 (English translation by A. de Grazia, 1953).

de la Vega-Leinert, A., Schröter, D., Leemans, R., Fritsch, U., and Pluimers, J.: A stakeholder dialogue on European vulnerability, Reg. Environ. Change, 8, 3, 109-124, 2008.

Dobler, A., Yaoming, M., Sharma, N., Kienberger, S., and Ahrens, B.: Regional climate projections in two alpine river basins: Upper Danube and Upper Brahmaputra, Adv. Sci. Res., this special volume, 2011.

EEA: Environmental Indicators: typology and overview, edited by: European Environment Agency (EEA), Technical report n. 25, available at: http://reports.eea.eu.int/TEC25/en/tab_ content_RLR (last access: March 2011), Copenhagen, 1999.

Giupponi, C., Sgobbi, A., Mysiak, J., Camera, R., and Fassio, A.: NetSyMoD - An Integrated Approach for Water Resources Management, in: Integrated Water Management, edited by: Meire, P., Coenen, M., Lombardo, C., Robba, M., and Sacile, R., Springer, Netherlands, 69-93, 2008.

Hutton, C. W., Kienberger, S., Amoako Johnson, F., Allan, A., Giannini, V., and Allen, R.: Vulnerability to Climate Change: People, Place and Exposure to Hazard, Adv. Sci. Res., this special volume, 2011.

IPCC: Emission Scenarios, edited by: Intergovernmental Panel on Climate Change (IPCC), Cambridge University Press, 2000.

Kienberger, S., Lang, S., and Zeil, P.: Spatial vulnerability units expert-based spatial modelling of socio-economic vulnerability in the Salzach catchment, Austria, Nat. Hazards Earth Syst. Sci., 9, 767-778, doi:10.5194/nhess-9-767-2009, 2009a.

Kienberger, S., Amoako Johnson, F., Zeil, P., Hutton,C., Lang, S., and Clark, M.: Modelling socio-economic vulnerability to floods: Comparison of methods developed for European and Asian case studies. Sustainable Development - a Challenge for European Research, Brussels, 2009b.

Ministerial Declaration of The Hague on Water Security in the 21st Century, 22 March 2000.

Mysiak, J., Giupponi, C., and Rosato, P.: Towards the development of a decision support system for water resource management, Environ. Modell. Softw., 20, 2, 203-214, 2005.

Reed, M.: Stakeholder participation for environmental management: A literature review, Biol. Conserv., 141, 2417-2431, 2008.

Renn, O.: Participatory processes for designing environmental policies, Land Use Policy, 23, 1, 34-43, 2006.

Sgobbi, A. and Giupponi, C.: Models and decision support systems for participatory decision making in integrated water resource management, in: CIHEAM-IAMB, Water saving in Mediterranean agriculture and future research needs, Options Méditerranéennes: Série B. Etudes et Recherches 56, Bari, Italy, 259-271, 2007.

TERI: Socio-economic Scenarios for Climate Change Impacts in India, Key sheet 3, DEFRA publication (UK), 2006. 